\title{
NEUROTECHNIX 2013
}

International Congress on Neurotechnology, Electronics and Informatics

VILAMOURA, Algarve, Portugal

18 - 20 SEPTEMBER, 2013

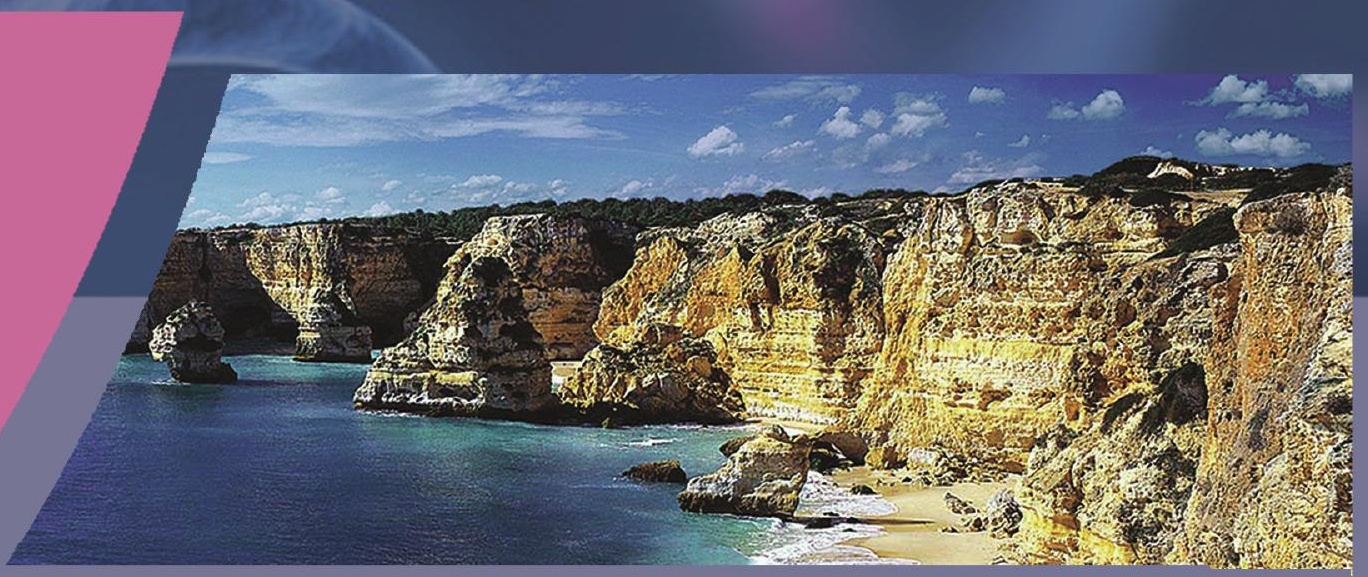

Complete Papers Submission Extension: June 3, 2013

Extended Abstracts Submission Extension: June 17, 2013

\author{
CONGRESS CHAIR Ana Rita Londral, Universidade de Lisboa, Portugal \\ PROGRAM CO-CHAIRS Pedro Encarnação, Universidade Católica Portuguesa, Portugal \\ Jose Luis Pons, Instituto de Automatica Industrial, Spain
}

\section{KEYNOTE SPEAKERS}

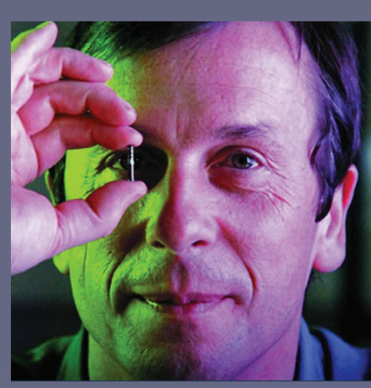

Kevin Warwick

University of Reading, United Kingdom

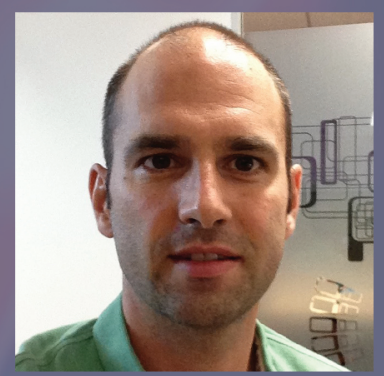

François Hug

University of Queensland, Australia

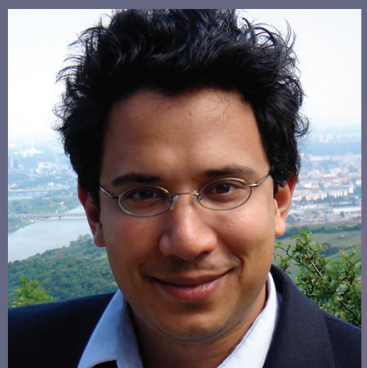

Aldo Faisal

Imperiall College

London,

United Kingdom

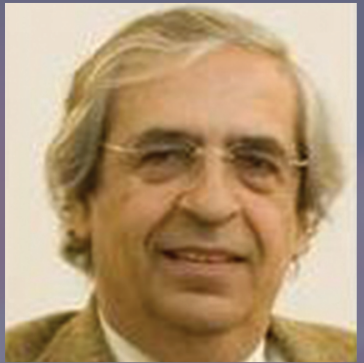

Alexandre Castro Caldas

Portuguese

Catholic University, Portugal

\section{MORE INFORMATION AT: WWW.NEUROTECHNIX.ORG}

Sponsored by:

IISTICE

In Cooperation with:

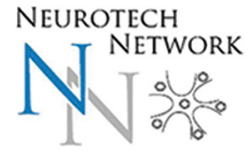

In Collaboration with:

antibodientine.com
Logistics Partner:

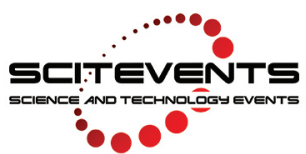

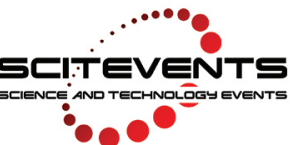

DIGTALARY

SCITEPRESS Digital Library
Springer Series
in Computational

Neuroscience

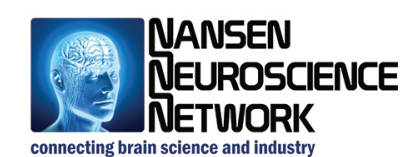

\section{APeence}

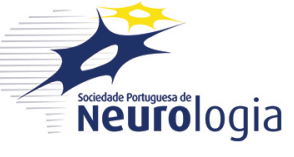

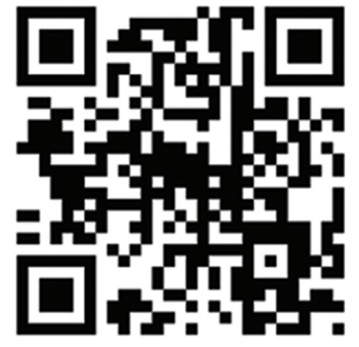

Scan and connect: www.neurotechnix.org

Procedings will be submitted for indexation by:

(3) THOMSON REUTERS CONFERENCE PROCEEDING
CITATION INDEX
夏 Inspec

o. uni-trier.de

웜 Computer Scien

$\epsilon$ 


\section{Actions}

On-line Registration

Submit a Paper

Authors Area

Reviewers Area

\section{Information}

Congress Details

Important Dates

Technical Program

Call for Papers

Program Committee/Reviewers

Partners

Become a Partner

R\&D Groups

Institutional

Partner Events

Media

Venue

Conference Venue

Reaching The Venue

Invited Speakers

Keynote Speakers

Satellite Events

Workshops

Symposia/Special Sessions

Tutorials

Demos

Panels

Authors Kit

Guidelines and Templates

Presentation Details

\section{Registration}

Registration Fees

Important Information

Travel and Accommodation

Reaching City

Visa Information

Hotel Reservation

Local Information

About City

What to see and do

Useful Information

Awards

Best Paper Award

Sponsored by:

\section{IIISTICC}

(e) MedlinRes

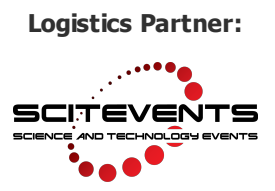

\section{Call for Papers}

\author{
Scope | Congress Areas | Keynote Speakers | Submission \\ Publication Important Dates | Secretariat | Venue \\ Congress Chair | Program Chair | Program Committee/Reviewers
}

NEUROTECHNIX is sponsored by INSTICC - Institute for Systems and Technologies of Information, Control and Communication

\section{SCOPE}

The first research works on neurotechnology can be dated back nearly half a century, but it is in the XXI century that most significant advances are being witnessed. Neurotechnology shows a very high potential of enhancing human activities, involving technologies such as biometrics, robotics, brain imaging, brain computer interfaces, and other combinations of neurological and biomedical knowledge with engineering technologies.

This congress will be a meeting point of both clinical and engineering professionals, academics and practitioners. It will promote translational discussions on how technology can meet clinical needs of both clinical practitioners and persons with neurological disorders.

Neurotechnix will emphasize research and application of neurotechnologies to different neurological disorders, such as: Neuromuscular diseases, Parkinson disease, Developmental disorders, Dementia, Epilepsy, Sleep disorders, Multiple Sclerosis, Neuroinfections, Brain Tumors, Stroke, Traumatic brain injuries, Cerebral Palsy, Spinal Cord Injury, Vision and Hearing disorders, among others.

Authors are invited to submit innovative research work that highlights new advancements of neurotechnology either in general or regarding a particular case, application or pathology. New ideas on how to approach neurotechnology challenges and issues will arise from the congress. Both clinical and engineering viewpoints are expected. Papers describing case studies, advanced prototypes, systems, tools and techniques and general survey papers indicating future directions are encouraged. Papers should describe original work in any of the topics listed below.

Presentations will confront engineering and clinical viewpoints for building consensus around the following areas:

1) new interventions,

2) objective evaluation and assessment of therapeutic programs,

3) assisted diagnosis,

4) effective implementation of technology driven services in neurological diseases.

\section{CONGRESS TOPICS}

- Brain Computer Interfaces

- Brain imaging

- Magnetic Resonance: MRI, NMRI and MRT

- EEG/ERP/EOG Signal Processing

- Sleep Analysis and Brain-firing Disorders

- Biometrics: Fingerprint, Face, Iris and Speaker Identification

- Biochips and Nanotechnology

- Biotechnology

- Robotics and Computer Vision

- Neurorobotics

- Neurocomputing

- Cybernetics

- Real time Monitoring of Neural Activity

- EMG Signal Processing and Applications

- Mobile and Embedded Devices

- Neuroscience - Drugs, Devices and Diagnostics

- Neurological Disorders and Rehabilitation

- Neuromodulation

- Neuro-interface Prosthetic Devices

- Social Impact of Neurotechnology

- Privacy, Security and Neuroethics

\section{KEYNOTE SPEAKERS}

Kevin Warwick, University of Reading, United Kingdom

François Hug, The University of Queensland, Australia

Aldo Faisal, Imperial College London, United Kingdom

Alexandre Castro-Caldas, Portuguese Catholic University, Portugal

\section{SUBMISSION}

Authors should submit either a complete paper or an extended abstract in English, carefully checked for correct grammar and spelling, addressing one or several of the congress areas or topics. Each submission should clearly indicate the nature of its technical/scientific contribution, and the problems, domains or environments to which it is applicable. To facilitate the double-blind paper evaluation method, authors are kindly requested to produce and provide their entry WITHOUT any reference to any of the authors, including the authors personal details, eventual acknowledgments and any other reference that may disclose the authors' identity.

Only original contributions should be submitted. Authors are advised to read INSTICC's ethical norms regarding plagiarism and self-plagiarism thoroughly before submitting and must make sure that their submissions do not substantially overlap work which has been published elsewhere or simultaneously submitted to a journal or another conference with proceedings. Papers or Extended Abstracts that contain any form of plagiarism will be rejected without reviews.

Authors can submit their work in the form of a Complete Paper, representing completed and validated research, or as an Extended Abstract. All entries must be submitted through the online submission platform PRIMORIS and should follow the instructions and templates that can be found under Guidelines and Templates. After the submission has been successfully completed, authors will receive an automatic confirmation e-mail. 
All accepted Extended Abstracts will be published in the Book of Abstracts of the congress and on CD-ROM support, without ISBN. All accepted Complete Papers (full and short) will be published in the Congress Proceedings, under an ISBN reference, on paper and on CDROM support. All papers presented at the congress venue will also be available at the SCITEPRESS Digital Library. SCITEPRESS is a member of CrossRef. The Congress Proceedings will be submitted to appropriate indexes for indexation.

\section{IMPORTANT DATES}

Congress Date: 18 - 20 September, 2013

Complete Paper Submission: June 3, 2013 (expired)

Authors Notification: July 8, 2013 (expired)

Camera Ready and Registration: July 24, 2013

\section{Extended Abstracts}

Paper Submission: June 17, 2013 (expired)

Authors Notification: July 12, 2013 (expired)

Camera Ready and Registration: July 25, 2013

\section{Special Session VirtRehab}

Paper Submission: June 30, 2013 (expired)

Authors Notification: July 12, 2013 (expired)

Camera Ready and Registration: July 25, 2013

\section{Special Session DeNeuro}

Paper Submission: July 22, 2013 (extended)

Authors Notification: July 30, 2013

Camera Ready and Registration: August 12, 2013

\section{Special Session FES - 50}

Paper Submission: July 22, 2013 (extended)

Authors Notification: July 30, 2013

Camera Ready and Registration: August 12, 2013

\section{Special Session SensoryFusion}

Paper Submission: June 24, 2013 (expired)

Authors Notification: July 12, 2013 (expired)

Camera Ready and Registration: July 25, 2013

\section{Special Session RoboAssist}

Paper Submission: June 30, 2013 (expired)

Authors Notification: July 22, 2013

Camera Ready and Registration: August 5, 2013

\section{Special Session DSS}

Paper Submission: July 22, 2013 (extended)

Authors Notification: July 30, 2013

Camera Ready and Registration: August 12, 2013

\section{Special Session BrainRehab}

Paper Submission: July 22, 2013 (extended)

Authors Notification: July 30, 2013

Camera Ready and Registration: August 12, 2013

\section{SECRETARIAT}

\section{NEUROTECHNIX Secretariat}

Address: Av. D. Manuel I, 27A, $2^{\circ}$ esq. 2910-595 Setúbal - Portugal

Tel.: +351265100033

Fax: +44 2030148813

e-mail: neurotechnix.secretariat@insticc.org

Web: http://www.neurotechnix.org/

\section{VENUE}

With the famous Marina on one side and its own concessioned beach on the other, the Tivoli Marina Vilamoura offers excellent facilities and quality service ensuring guests a memorable stay in Portugal. The lively social and nightlife of Vilamoura attracts many national and international celebrities from different areas who come to enjoy holidays and weekends of complete relaxation, where there is plenty to do such as water sports, golf and sightseeing.

\section{CONGRESS CHAIR}

Ana Rita Londral, Universidade de Lisboa, Portugal

\section{PROGRAM CO-CHAIRS}

Pedro Encarnação, Universidade Católica Portuguesa, Portugal

Jose Luis Pons, Instituto de Automatica Industrial, Spain

\section{PROGRAM COMMITTEE/REVIEWERS}

Mai S. Mabrouk, Misr University for Science and Technology, Egypt

Chester A. Mathis, University of Pittsburgh, United States

Amr Abdel-Dayem, Laurentian University, Canada

Ajith Abraham, Machine Intelligence research Labs (MIR Labs), United States

Gregor Adriany, University of Minnesota, United States

Lyuba Alboul, Sheffield Hallam University, United Kingdom

Pedro Almeida, University of Lisbon, Portugal

Jesús B. Alonso, Universidad de Las Palmas de Gran Canaria, Spain

Abbes Amira, The university of the West of Scotland, United Kingdom 
Alexandre Andrade, Faculdade de Ciências da Universidade de Lisboa, Portugal

Helder Araújo, University of Coimbra, Portugal

Sabri Arik, Istanbul University, Turkey

Tetsuya Asai, Hokkaido University, Japan

Jose M. Azorin, Miguel Hernandez University, Spain

Reneta Barneva, State University of New York, United States

Ammar Belatreche, University of Ulster, United Kingdom

Alexandre Bernardino, Instituto Superior Técnico, Portugal

Elia Biganzoli, Università degli Studi di Milano, Italy

Martin Bogdan, Universität Leipzig, Germany

Fernando Brunetti, Consejo Superior de Investigaciones Científicas, Spain

Rodrigo Capobiaco Guido, University of São Paulo, Brazil

Barbara Caputo, IDIAP Research Institute, Switzerland

Mamede de Carvalho, Institute of Physiology, Faculty of Medicine- University of Lisbon, Portugal

Francis Castanie, TeSA, France

Xin Chen, Georgia Health Sciences University, United States

Albert C. S. Chung, The Hong Kong University of Science and Technology, Hong Kong

Krzysztof Cios, Virginia Commonwealth University, United States

Joao Paulo Costeira, ISR/IST - TechnicalUniversity of Lisbon, Portugal

Lopes da Silva, University of Amsterdam, Netherlands

Alessandro De Mauro, Vicomtech-IK4, Spain

Lei Ding, University of Oklahoma, United States

Dominique Durand, Case Western Reserve, United States

Gary Egan, Monash University, Australia

Dagan (David) Feng, The University of Sydney, Australia

Patrícia Figueiredo, Instituto Superior Técnico, Portugal

Alexander Fingelkurts, BM-Science - Brain \& Mind Technologies Research Centre, Finland

Andrew Fingelkurts, BM-Science - Brain \& Mind Technologies Research Centre, Finland

Mário Forjaz Secca, CEFITEC, Departamento de Fisica, FCT/UNL, Portugal

Anselmo Frizera, UFES, Brazil

Colin Fyfe, University of the West of Scotland, United Kingdom

Philippe G. Young, University of Exeter, United Kingdom

Vasco Galhardo, Faculdade de Medicina - Universidade do Porto, Portugal

Petia Georgieva, University of Aveiro, Portugal

Michele Giugliano, University of Antwerp, Belgium

Sónia Gonçalves, Faculdade de Medicina da Universidade de Coimbra, Portugal

Jordi Gonzàlez, Universitat Autònoma de Barcelona - Centre de Visió per Computador, Spain

Cuntai Guan, ASTAR, Singapore

Jay Gunkelman, Brain Science International, United States

Xavier Intes, Rensselaer Polytechnic Institute, United States

Mark J. Embrechts, Rensselaer Polytechnic Institute, United States

Thomas J. R. Hughes, University of Texas, United States

António J. R. Neves, University of Aveiro, Portugal

Er Meng Joo, Nanyang Technological University, Singapore

Pasi Karjalainen, University of Eastern Finland, Finland

Jonghwa Kim, University of Augsburg, Germany

Frank Kirchner, DFKI, Germany

Andrzej Kloczkowski, Ohio State University, United States

Constantine Kotropoulos, Aristotle University of Thessaloniki, Greece

Ondrej Krejcar, University of Hradec Kralove, Czech Republic

Elmar Lang, Universität Regensburg, Germany

Martin Lauterbach, Hospital da Luz, Portugal

Hongen Liao, The University of Tokyo, Japan

Diego Liberati, National Research Council, Italy

Xiao Liu, Brunel University, United Kingdom

Christos Loizou, Intercollege, Cyprus

Nigel Lovell, University of New South Wales, Australia

Jose Luis Contreras-Vidal, University of Houston, United States

Calogero Maria Oddo, Scuola Superiore Sant'Anna, Italy

Javier Melenchón, Universitat Oberta de Catalunya, Spain

Paulo Mendes, University of Minho, Portugal

Silvestro Micera, Ecole Polytechnique Federale de Lausanne, Switzerland

Claudio Moraga, University of Dortmund, Germany

Susana Novais, Carnegie Mellon University, United States

Urbano Nunes, Instituto De Sistemas E Robotica, Portugal

Haluk Ogmen, University of Houston, United States

Joao Papa, Sao Paulo State University - Unesp, Brazil

Nathalia Peixoto, Neural Engineering Lab, George Mason University, United States

Francisco Perales, Uib, Spain

George Perry, University of Texas at San Antonio, United States

Victor Pikov, Huntington Medical Research Institutes, United States

Armando J. Pinho, University of Aveiro, Portugal

Anabela Pinto, University of Lisbon - Faculty of Medicine, Portugal

Susana Pinto, Institute of Molecular Medicine - Faculty of Medicine, University of Lisbon, Portugal

Gabriel Pires, Institute for Systems and Robotics - Coimbra / Polytechnic Institute of Tomar, Portugal

Hemerson Pistori, Dom Bosco Catholic University, Brazil

Mirjana Popovic, University of Belgrade, Serbia

Domenico Pratico, Temple University, United States

José C. Príncipe, University of Florida, United States

Ales Prochazka, Institute of Chemical Technology, Czech Republic

Hugo Proença, University of Beira Interior, Portugal

Rafael Raya, Spanish National Council for Science Research, Spain

Raúl Rojas, Freie Universität Berlin, Germany

Renaud Ronsse, Université catholique de Louvaine, Belgium

Wim Rutten, University of Twente, Netherlands

João Sanches, Institute for Systems and Robotics, Portugal

Despina Sanoudou, Medical School, University of Athens, Greece

José Santos-Victor, Instituto Superior Técnico, Portugal

André Saúde, Federal University of Lavras, Brazil

Mohamad Sawan, Ecole Polytechnique de Montreal, Canada

Friedhelm Schwenker, University of Ulm, Germany

Tapio Seppänen, University of Oulu, Finland

Fiorella Sgallari, University of Bologna, Italy

Claudia Sommer, University of Würzburg, Germany

Armando J. Sousa, Faculdade de Engenharia da Universidade do Porto, Portugal

Sundaram Suresh, .Nanyang Technological University, Singapore

Jimmy T. Efird, East Carolina Heart Institute, United States 
João Manuel R. S. Tavares, FEUP - Faculdade de Engenharia da Universidade do Porto, Portugal

Miguel Tavares da Silva, Instituto Superior Técnico, Portugal

Marc Tittgemeyer, Max-Planck-Institut für neurologische Forschung, Germany

Diego Torricelli, Consejo Superior de Investigaciones Cientificas (CSIC), Spain

Carlos M. Travieso, University of Las Palmas de Gran Canaria, Spain

Shrutin Ulman, Agnel Polytechnic, India

Nicola Vitiello, Scuola Superiore Sant'Anna, Italy

Chung $Y$. Hsu, China Medical University, Taiwan

Zeyun Yu, University of Wisconsin at Milwaukee, United States

Inga Zerr, University of Göttingen, Germany

Y-T Zhang, The Chinese University of Hong Kong, China

Chun Zhang, Tsinghua University, China

Djemel Ziou, Universite de Sherbrooke, Canada 


\title{
Conference Program - Thursday September 19
}

\author{
Wednesday Thursday Friday
}

09:15

\section{9:15 - 11:00 - Room Gemini II \\ Parallel Session 2 - VirtRehab}

- 1: Virtual Arm Representation and Multimodal Monitoring for the Upper Limb Robot Assisted Teletherapy

Gorka Epelde, Xabier Valencia, Aitor Ardanza, Elsa Fanchon, Alessandro De Mauro, Francisco Molina Rueda, Eduardo Carrasco and Shabs Rajasekharan

- 6: Hand Functional Recovery in Sub-acute Brain Injury Stage Patients using AMADEO® Robotic-assisted Therapy - A Pilot Clinical Study with Apraxic and Neglect Patients

Pedro A. Serrano López-Terradas, Diana Moya Rosendo and Marcos Ríos Lago

- 7: New Developments in the Gesture Therapy Platform - Past, Present and Future of our Research

Felipe Orihuela-Espina, Paloma Álvarez-Cardenas, Lorena Palafox, Israel Sánchez-Villavicencio, Alberto L. Morán, Jorge Hérnandez-Franco and Luis Enrique Sucar

11:00 Coffee-Break (11:00 - 11:30)

$11: 30$

11:30 - 13:00 - Room Gemini III

Parallel Session 3

- 5: Does an Angry Salesman Scary the Students of University of Silesia? Visual ERP Studies

Karina Maciejewska and Zofia Drzazga

- 8: Separation of Auditory Evoked Responses to the Right- and Left-Ear Inputs S. Kuriki, H. Kurumaya, K. Tanaka and Y. Uchikawa

- 10: Carrier Frequency Specificity of Short-sound Elicited Auditory SteadyState Response and Effect of Animation Presentation Keita Tanaka, Fumie Kudo, Shinya Kuriki and Yoshinori Uchikawa

- 13: Memory and Processing Efficient Formula for Moving Variance Calculation in EEG and EMG Signal Processing

Mario Michael Krell, Marc Tabie, Hendrik Wöhrle and Elsa Andrea Kirchner

- 15: A Dataflow-based Mobile Brain Reading System on Chip with Supervised Online Calibration - For Usage without Acquisition of Training Data Hendrik Woehrle, Johannes Teiwes, Mario Michael Krell, Elsa Andrea Kirchner and Frank Kirchner

\section{1:30 - 13:00 - Room Gemini II}

\section{Parallel Session 3 - VirtRehab}

- 2: Clinical, Functional and Kinematic Correlations using the Virtual Reality System Toyra ${ }^{\circledR}$ as Upper Limb Rehabilitation Tool in People with Spinal Cord Injury

Iris Dimbwadyo-Terrer, Fernando Trincado-Alonso, Ana de los Reyes-

Guzmán, Alberto Bernal-Sahún, Patricia López-Monteagudo, Begoña PolonioLópez and Ángel Gil-Agudo

- 4: Rehabilitation for Children while Playing with a Robotic Assistant in a Serious Game

L. V. Calderita, P. Bustos, C. Suárez Mejías, B. Ferrer González and A. Randera 
- 5: Illusion Approach for Upper Limb Motor Rehabilitation Yee Mon Aung and Adel Al-Jumaily

13:00 Lunch (13:00 - 14:30)

$14: 30$

\section{4:30 - 16:00 - Room Gemini II}

Parallel Session 4

- 12: Striving for Better and Earlier Movement Prediction by Postprocessing of Classification Scores

Sirko Straube, Anett Seeland and David Feess

- 20: Automated Algorithm for Synchronized Quantification of LFP Recordings and Individual Behavioural Parameters in an Animal Model for OCD T. Tambuyzer, H. Wu, K. Bauweleers, Kris van Kuyck, B. Nuttin and J.-m Aerts

- 22: Command-line Electrophysiology - A Closed-loop Approach to Single Cell Characterisation João Couto, Daniele Linaro and Michele Giugliano

- 25: Comparison of Neural Networks for Prediction of Sleep Apnea Yashar Maali and Adel Al-Jumaily

16:00 Coffee-Break (16:00 - 16:30)

16:30 - 18:00 - Room Gemini II

Parallel Session 5

- 16: A Low Cost Platform based on FES and Muscle Synergies for Postural Control Research and Rehabilitation

D. Galeano , F. Brunetti, D. Torricelli, S. Piazza and J. L. Pons

- 11: Comparison of Parametric and Non-Parametric Spectral Estimation Methods for Automatic Tremor Detection against Clinical Evaluation O. Martinez-Manzanera, J. H. Elting, J. W. van der Hoeven and N. M. Maurits

- 17: A Method to Detect Keystrokes using Accelerometry to Quantify Typing Rate and Monitor Neurodegenerative Progression

Ana Londral, Mafalda Câmara, Hugo Gamboa, Mamede de Carvalho, Anabela Pinto and Luís Azevedo

- 24: Neuromuscular Electrical Stimulation and Biofeedback Therapy to Improve Endometrial Growth in Patients with Thin Endometrium - A Randomized Controlled Study

Madafeitom Meheza Abide Bodombossou Djobo, Xiaoli Chen, Zhuangyu He,

Xiaomiao Zhao, Shaoqing Chen, Qingxue Zhang and Dongzi Yang

\section{6:30 - 18:00 - Room Gemini III}

Parallel Session 5 - BrainRehab

- 1: Dynamics of a Stimulation-evoked ECoG Potential During Stroke Rehabilitation - A Case Study Armin Walter, Georgios Naros, Martin Spüler, Wolfgang Rosenstiel, Alireza Gharabaghi and Martin Bogdan

- 2: Efficiency of SSVEF Recognition from the Magnetoencephalogram - A Comparison of Spectral Feature Classification and CCA-based Prediction Christoph Reichert, Matthias Kennel, Rudolf Kruse, Hermann Hinrichs and Jochem W. Rieger

- 3: ECoG Real Time Signal Processing for Clinical Self paced BCI Application Nana Arizumi, Guillaume Charvet, Andrey Eliseyev, Jérémy Pradal, Serpil Cokgungor, Nicolas Tarrin, Corinne Mestais, Tetiana Aksenova and AlimLouis Benabid

- 4: A Serious Game Application using EEG-based Brain Computer Interface Francisco José Perales and Esperança Amengual

- 5: Monitoring Depth of Hypnosis under Propofol General Anaesthesia Grancer Caulsality and Hidden Markovy Models 


\title{
Illusion Approach for Upper Limb Motor Rehabilitation
}

\author{
Yee Mon Aung and Adel Al-Jumaily \\ Schoolof Electrical, Mechanical and Mechatronic Systems, Faculty of Engineering, \\ University of Technology Sydney, 15 Broadway, Ultimo, NSW 2007, Australia \\ yee.m.aung@student.uts.edu.au,adel.al-jumaily@uts.edu.au
}

Keywords: $\quad$ Upper Limb Rehabilitation, Augmented Reality Therapy and Illusion based Motor Rehabilitation.

\begin{abstract}
Taking the advantage of human brain plasticity nature, Augmented Reality (AR) based Illusion System (ARIS) for upper limb rehabilitation has developed. The ARIS aims to restore the lost functions of upper limb due to various motor injuries. It incorporates with AR technology to build up the upper limb rehabilitation exercise and computer vision with color recognition technique to comply "Fool-the-Brain" concept for fast recovery of neural impairments. The upper limb exercise that developed in ARIS is to promote the impaired arm range of motion by moving along the predefined trajectory of the AR based exercise. In ARIS, the real impaired arm will be overlapped by the virtual arm throughout the rehabilitation exercise to create the illusion scene. In the case of real arm cannot perform the required task, virtual arm will take over the job of real one and will let the user to perceive the sense that he/she is still able to perform the reaching movement by own effort to the destination point which is the main idea of ARIS. The validation of ARIS was conducted as a preliminary stage and the outcome are discussed.
\end{abstract}

\section{INTRODUCTION}

Neurotrauma such as Traumatic Brain Injury (TBI), Spinal Cord Injury (SCI) or Stroke survivors are facing with functional neurological deficit including motor deficit resulting loss of control over whole body or one side of the body in accordance with the degree of impairment. Therefore, patients cannot perform the daily live activities and this will greatly impact their quality of life. According to the Physical Disability Australia (PDA), it was estimated that $13 \%$ of the Australian population have suffered from physical disabilities that limits the mobility and selfcare activities (Physical Disability Australia., 2013). To improve such limitations, rehabilitation is essential to perform. Rehabilitation is the physical therapy that regains mobility, strength of muscles and relearning skills. Research studies had proven that the motor impairment can be treated by intense use of active movement in repetitive tasks and taskorientated activities which will result in improving motor skills and muscular strength by preventing muscle spasticity, muscle atrophy and osteoporosis (Riener et al., 2005). Thus, a lot of researchers have been trying to develop low cost effective rehabilitation systems by employing various technologies that including virtual reality and augmented reality for therapeutic purposes as these technologies have proven their effectiveness in the area of upper limb rehabilitation (Al-Issa et al., 2012).

This paper provides a short review of recent developments for upper limb rehabilitation with augmented reality technology. Following a brief overview, the proposed novel system will be described which is AR based Illusion System (ARIS) for upper limb rehabilitation. The proposed system integrates physical and psychological rehabilitation possibilities for fast recovery in upper limb motor deficit. In term of physical rehabilitation, AR based reaching exercise has developed to attain the wider range of movements at shoulder joint. In term of psychological rehabilitation, ARIS employs "Foolthe-Brian" concept to create the "illusion scene" to provide "fool the sense" to the patients. This concept will provide with artificial visual feedback to the system user to reestablish the neural pathways and synapses that able to control the mobility by oneself. The term "Fool-the-Brain" was defined by the group of researchers from (Giraux and Sirigu, 2003) as their studies had proven that motor cortex activity was able to restore successfully by illusory movements of paralyzed limb and able to "fool" the brain to improve the arm/hand movements. It is because of the ability of human neuroplasticity which is 
mediated by beliefs, perceptions and emotions that react in ever-changing ways, through thoughts and activities based on environmental input.

\section{RELATED WORK}

Recently, Augmented Reality (AR) technologies in upper limb rehabilitation area provide promising results as a useful tools for physical, psychological and occupational therapies. AR is the combination of real and virtual environment where virtual objects lay on top of the real environment which is fed by camera as a live video background image on the computer display screen. Therefore, this approach will provide better interactive training environment and more realistic. As far as AR based upper limb rehabilitation systems are concern, researchers in (Aung et al., 2012a; Dinevan et al., 2011) have developed AR based system to promote the reaching movements of upper limb and strengthen the associated muscles. Our group has previously developed AR based upper limb rehabilitation system which integrated with biofeedback system to access the performance of trained muscles and provide with more motivational approach (Aung et al., 2012b; Aung and Al-Jumaily, 2013). In terms of "Fool-the-Brain" concept, the motivation is arisen from the positive results of mirror box therapy (Lin et al., 2012) and TeraMem System (Regenbrecht et al., 2012) which has employed "Fool-the-Brain" concept successfully. The numbers of studies have embarked on employing mirror therapy to enhance motor deficit and provide with positive results (Lee et al., 2012; Thieme et al., 2013).

However, up to our knowledge, the existing developments based on this concept are only developed with forearm and/or hand rehabilitation with mirror box to attain the artificial visual feedback. Therefore, the very first novel system that training for the whole arm with artificial visual feedback is proposed in this paper. The detail of the development is described in the following section.

\section{DEVELOPMENT OF "ARIS"}

The AR based Illusion System (ARIS) is a low cost rehabilitation system that only requires PC with cheap webcam and any color as a marker. Employing of AR technology in ARIS aims to motivate the patients' willpower to perform the long term rehabilitation therapy. The ARIS is developed in Adobe Flash Professional CS6 platform. It works based on capturing the video scenes, displaying of virtual objects, manipulating of 3D Virtual Arm (VA) that is loaded with Papervision 3D, detecting the color marker and checking for the collision detection between marker and virtual objects. The system architecture and the development of the ARIS detail as below.

\subsection{System Architecture}

The overall architecture of the proposed system is shown in figure 1. The upper limb rehabilitation therapy system starts with displaying the therapy window on the monitor that includes the information for user, rehabilitation exercise and tracking result. Then, the system will request the permission to access the webcam to start the therapy. Once user allows the webcam access, live video image will feed at the defined position on the therapy window. This live video will serve as a background for AR based rehabilitation exercise. Subsequently, the user will be requested to click on the desired color at shoulder joint to track the current joint position and then the shoulder joint of Virtual Arm (VA) will be attached at clicked position. This attachment will overlay the virtual arm on top of the real impaired arm to perceive "fool-the-brain" concept from user.

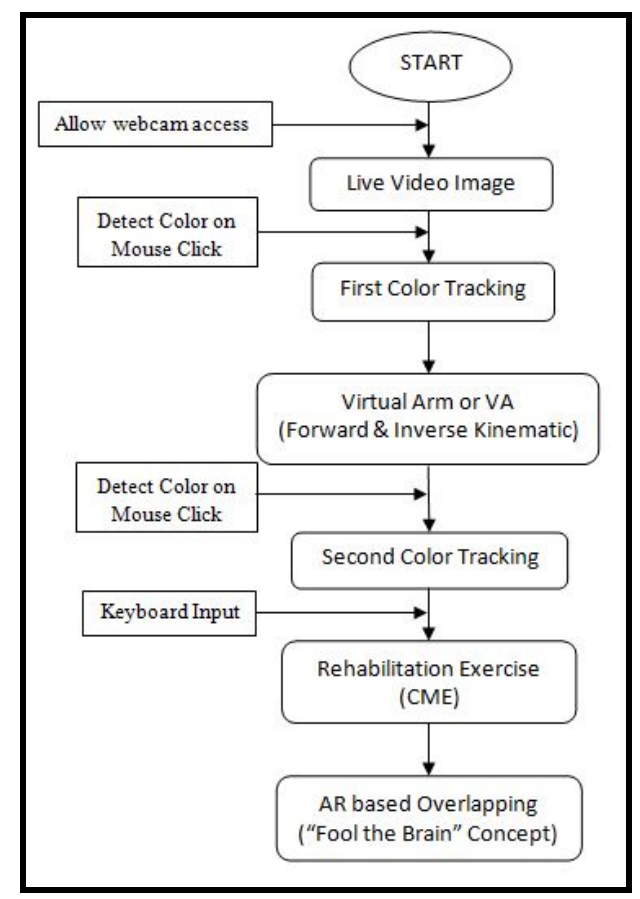

Figure 1: System Architecture. 
After that, the user will be requested to click again on second color at wrist joint and this selected color will interact with virtual objects to perform the rehabilitation exercise. After all of the above steps are completed, the user/therapist will have to press the keyboard to activate the exercise and auto movement of VA. The developed system allows the user and therapist to monitor the performance of real arm motion under "Real Arm Trajectory Graph" in therapy window. The complete system is made up of four different modules: computer vision and multicolour tracking, modelling of virtual arm, modelling of kinematic chain and AR based upper limb rehabilitation exercise as depicted in figure 2 . The detail developments of each module are explained in the following sections.

\subsection{Modelling of Virtual Arm}

The Virtual Arm (VA) is created in blender software as portrayed in figure 2(b) and then exported as ".dae" format to load in the Adobe Flash CS6 via Papervision 3D which is an open source real-time 3D engine for Flash. In blender software, the arm kinematic chain is defined correctly in such a way that the upper arm as a parent link of the forearm link, the forearm link as a parent link of the hand link. This arrangement will ensure any motion of the parent link will have an effect on the child link during simulation. The defining of pivot point on each link is very important as this will define the centre of rotation of the link joint and is carefully defined in developed VA. After developing VA in blender software, the kinematic model of the VA is developed as shown in figure 2(c). In the kinematic model, the shoulder joint is considered as spherical joint that permits the wide range of joint motions. However in this paper, the shoulder joint is limited to $3 \mathrm{DOF}$, the elbow joint, forearm and wrist joint is modelled as cylindrical joint which allows the flexion/extension of the elbow and wrist and internal rotation of the forearm with $1 \mathrm{DOF}$ each. Therefore

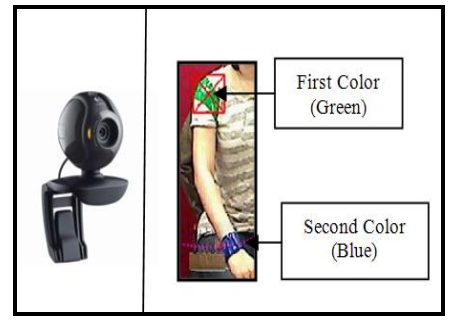

(a)

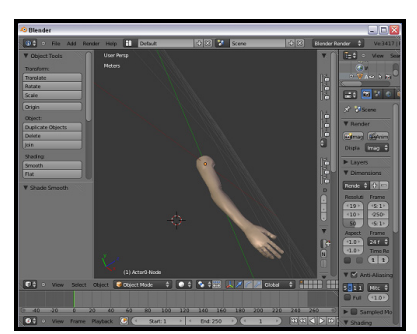

(b) total of 6DOF model is developed and DenavitHartenberg (D-H) parameters are assigned for kinematics calculation as detail in next section.

\subsection{Modelling of Kinematics Chain}

The mathematical modeling of VA was formulated with Denavit-Hartenberg (D-H) convention (Denavit \& Hartenberg, 1964). The D-H model was created by relating each link's frame of reference on the virtual arm with the preceding link frame of reference. The four parameters: $a, \alpha, d$ and $\theta$ which represents the link length, link twist, link offset and joint angle, respectively are defined at respective joint as shown in Table 1.

Table 1: D-H parameters and anatomical motion and limit.

\begin{tabular}{|c|c|c|c|c|c|c|c|}
\hline \multicolumn{2}{|c|}{ Joint } & Motion & $\alpha$ & a & $\theta$ & d & Joint Limit \\
\hline 1 & \multirow{3}{*}{ Shoulder } & Internal/External Rotation & $-\pi / 2$ & 0 & $\theta_{1}$ & 0 & $\left(-90^{\circ}, 30^{\circ}\right)$ \\
\hline 2 & & Abduction/Adduction & $\pi / 2$ & 0 & $\theta_{2}$ & 0 & $\left(-40^{\circ}, 180^{\circ}\right)$ \\
\hline 3 & & Flexion/Extension & 0 & L3 & $\theta_{3}$ & 0 & $\left(0^{\circ}, 180^{\circ}\right)$ \\
\hline 4 & Elbow & Flexion/Extension & 0 & L4 & $\theta_{4}$ & 0 & $\left(0^{\circ}, 130^{\circ}\right)$ \\
\hline 5 & Wrist & Flexion/Extension & $\pi / 2$ & 0 & $\theta_{5}$ & 0 & $\left(-45^{\circ}, 45^{\circ}\right)$ \\
\hline 6 & Forearm & Internal/External Rotation & 0 & L6 & $\theta_{6}$ & 0 & $\left(0^{\circ}, 160^{\circ}\right)$ \\
\hline
\end{tabular}

The frame of reference is established depending on the translation and rotation in $x$-axis (a and $\alpha$ ) and the translation and rotation in $\mathrm{z}$-axis $(\mathrm{d}$ and $\theta)$. Each property used in D-H convention is constant, except if the joint is a revolute type, link twist " $\alpha$ " is variable, or when the joint is prismatic, link offset "d" is variable. Although the real arm has wider articulation range, the VA is limited to safe articulation range and the values of such range, D-H parameters of VA and anatomical motions with respect to joints are presented in Table 1. Forward and inverse kinematics calculation is performed to reach the predefined position according to the desired trajectory that based on developed exercise. The inverse kinematic is computed for each link angle, following the link by link downward from shoulder to wrist.

Figure 2: Individual module in ARIS (a) Computer vision \& multicolor tracking (b) Modeling of virtual arm (c) modeling

of kinematic chain (d) AR based rehabilitation exercise.

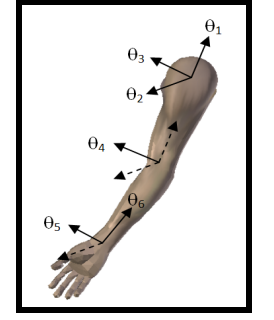

(c)

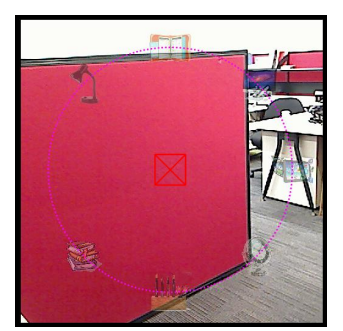

(d) 
There are total in seven desired points that real arm and VA require to move as an upper limb rehabilitation exercise which is in circular motion. The circular motion as a rehabilitation exercise has been chosen and development will be explained in the following section.

\subsection{AR based Rehabilitation Exercise}

Rehabilitation exercise is essential for post stroke patients and any motor injured patients as this will help the patients to improve their lost functions by performing repetitive tasks and task-oriented activities. To perform such repetitive task-oriented movement, Circular Motion Exercise (CME) has developed in ARIS. The trajectory of CME is chosen as the circular motion because it involves almost largest range of motion of the shoulder articulations such as shoulder flexion, adduction and abduction, internal and external rotation which is an optimum goal to achieve as upper limb rehabilitation. CME is built based on AR technology where virtual world and real world are merged.

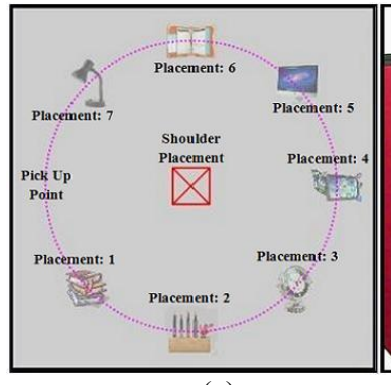

(a)

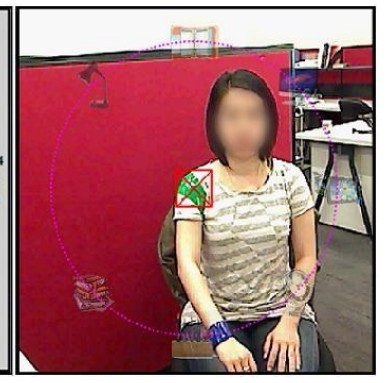

(b)
Figure 3: Circular Motion Exercise (CME) for Upper Limb Rehabilitation (a) Without video Background (b) With video Background.

The aim of the CME is to collect the virtual objects that indicated by animated arrows and place them on the respective transparent virtual objects that are displayed on the screen. The screen shot of CME is portrayed in figure 3 . There are total of seven virtual objects that user requires to pick and place as shown in the figure 3(a). To pick the virtual object, user requires moving his/her arm to pick up point and then the color that selected at wrist joint (in this case is blue color) will check the collision detection with virtual object. If the color and the virtual object are collided to each other, it defines as picking of the object and then virtual object will attach to the color at wrist joint. This will appear on the display screen as user is picking up the virtual object. When the object reaches to placing position, the collision between virtual object and predefined placing position will check again to place the virtual object. The place positions of all seven virtual objects are appeared as same translucent virtual objects in circular shape for easy understanding.

The rehabilitation purpose of the CME is to provide the wider range of motion at shoulder joint which is one of the most important exercises in rehabilitation hospital. By performing CME, user arm will train in shoulder flexion, abduction, adduction, internal and external rotation movements. As a result, the associated muscles that involved in these movements will be trained and strengthen over time.

\subsection{Multicolour Tracking}

In this work, only two joints: shoulder joint and wrist joint position are interested to be tracked as the current position of that particular joint. The shoulder joint position is required to overlay the VA so that wherever the real shoulder joint is captured by webcam, the VA will always overlay correctly on top of the real arm and display on the monitor. As for wrist joint position, this is where interacting with real hand and virtual object collision is occurred.

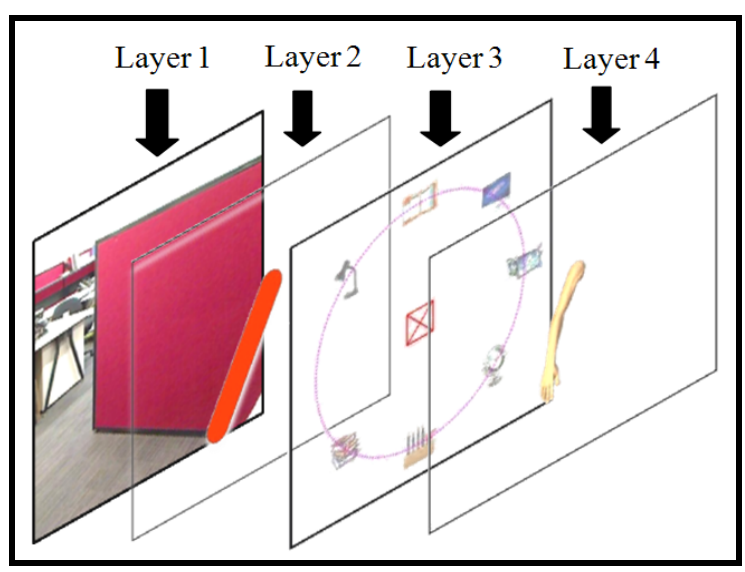

Figure 4: Four layer to built up "Fool-the-Brain" concept.

Another purpose of the wrist joint tracking is to track the performance of the real hand trajectory that user and therapist are able to monitor. This performance can be observed in real-time under "Real Arm Trajectory Graph" in the therapy window. Therefore, we have developed multicolor tracking algorithm that the system is able to track the multiple colors properly with minimum effect due to the surrounding light changes. 


\section{4 "FOOL-THE-BRAIN" CONCEPT}

In ARIS, "Fool-the-Brain" concept is developed via overlaying of live video image and virtual objects with multiple layers to create the illusion of user's perception. The idea of overlaying concept is as portrayed in figure 4 . There are four layers in total to achieve the concept. The very first layer is fed with live video image to create AR environment. On top of that layer, rectangular shape with rounded edges object is overlaid which defined as second layer. In this layer, webcam captured image is imported. However, this imported image can be only seen inside of the rectangular shape object. The rest of the region (out of rectangle shape) is set as transparent so that the active region is only inside the rectangular shape object. By overlaying the rectangular object, this will appear as covering the actual human arm on the display screen and will appear as removing of real arm on the display screen. The placement of the rectangular shape object is attached to the user defined color at shoulder joint. Therefore, current position of the real arm will be always tracked and overlapped with user's arm size image which captured via webcam wherever the user's arm moves. Then the CME will overlay at third layer in ARIS to serve as an upper limb rehabilitation exercise. At fourth layer, VA will be overlaid on top of the real arm and appear as it is covering on top of rectangular shape object. Therefore, this appearance will create the illusion as a user real arm. This means that the real arm of the user will be removed and replaced with VA by means of computer vision and color tracking technique. Therefore, from the user point of view, he/she will perceive the VA as his/her own arm. When CME start, both VA and real arm will move together to reach the desired position where the real arm is moved by user effort and VA will move by predefined trajectory via inverse kinematic. In the case of real arm cannot reach to the desired position, VA will take over the job of real arm as if the user arm is still moving and reach to the desired position while the real arm is covered up with rectangular shape object with same background of live webcam so that user will not see his/her real arm. This will let the user to perceive the sense that he/she is still able to perform the reaching exercise by his/her own impaired arm to the destination point. This sense will help the patients in fast recovery of motor impairment due to human brain plasticity.

\section{PROOF OF CONCEPT STUDY}

Non-clinical study has tested for novelty aspects of overlaying or illusion, augmentation and believability. In this work, a healthy subject (user) is requested to sit in front of the computer monitor and webcam. After that, ARIS program will run and the therapy window is appeared on the display screen. The instruction on how to perform the rehabilitation exercise and its step by step procedure is stated at the right bottom of the therapy window. The current $\mathrm{X}, \mathrm{Y}, \mathrm{Z}$ positions and joint angle values of shoulder, elbow and wrist joints of the VA is able to monitor by the user in real-time on the therapy window. Before the rehabilitation exercise starts, the request command for the webcam is appeared. After user has accepted the request, seven translucent virtual objects are appeared which displayed in circular shape on top of the real-time video background image. Then the user is asked to select the color at shoulder joint (in this case is green). Once the color has chosen at shoulder joint, VA is appeared on top of the real arm that capture by webcam. The VA that overlay on top of the real arm is moved and tracked correctly according to the real arm movement. This shows that the developed tracking algorithm is able to track quite accurately and less response to light changes. Once VA is overlapped, the user is asked again to choose another color at the real wrist joint that captured by webcam (in this case is blue). Then, the system calculates the distance between the shoulder joint and wrist joint to calculate the length of rectangular shape object. Subsequently, the webcam captured image is cover up on top of the real arm. After that the selected color is interacted with seven virtual objects to perform pick and place action. We observed that the real arm is successfully covered up and picking and placing of virtual objects are able to perform smoothly. The collision detection method that checking the pixels distance between wrist color marker and virtual object is able to detect precisely. Throughout the performing of rehabilitation exercise, VA is able to move according to the predefined trajectory which is driven by forward and inverse kinematic algorithm. The desired position and joints angles are able to be displayed correctly on the therapy window as well. The testing of overtaking task has also conducted where if there is a case that the real arm cannot move to the desired position. It has found that VA is successfully continued to carry out the task by placing the virtual objects at desired positions. This approves that "Fool-the-Brain" concept is successfully adopted in this development. The 
tracking of real hand movement is able to monitor in real-time under "Real Arm Trajectory Graph" effectively. The screen shot of the proof of study is depicted in figure 5 .

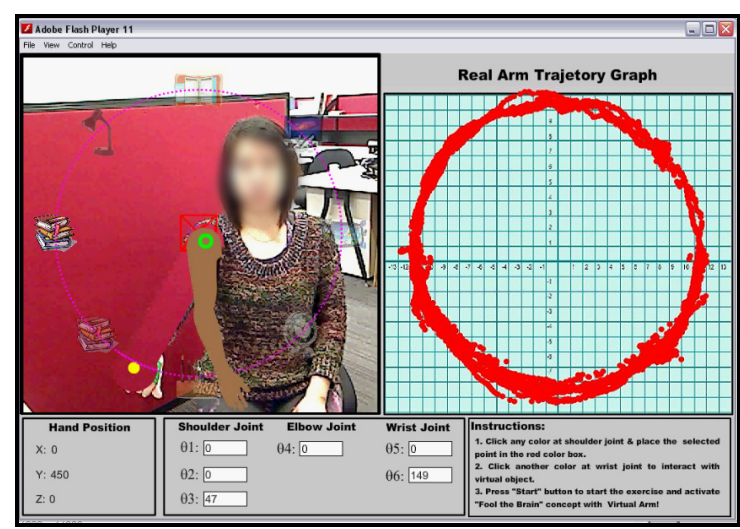

Figure 5: Result from proof of concept study.

\section{CONCLUSIONS AND FUTURE WORK}

In this paper, ARIS was developed to improve the upper limb range of motion especially for shoulder joint motion with "Fool-the-Brain" concept. The AR based computer game is chosen as a rehabilitation exercise as integrating with AR technology in rehabilitation field provides high motivation for long term training. Therefore, AR based CME was developed in ARIS to attain the wide range of shoulder joint motions via reaching exercise. Throughout the performing of CME rehabilitation exercise, the real arm was overlapped by VA model to fool the user perception to attain artificial visual feedback that provides fast recovery of user's neural impairment. If the user cannot reach to the particular point, VA will take over the job of real arm and will let the user to perceive the sense that he/she is still able to perform the reaching movement by own effort to that particular point. Non-clinical study was conducted to validate the novelty aspects of ARIS and provided with positive observations to carry on with future works.

As far as future work is concerned, improvement of the appearance of the VA model will be made. The model will be replaced with user skin texture that can be adjusted according to the individual user complexion. This will perceive the more realistic appearance of virtual arm as a real user arm. To make it more effective rehabilitation system, the system will be integrated with biofeedback system to detect the intended movement of the user via surface eletromygraphy (sEMG) signals. Non-clinical trials with more participants will be conducted in near future to attain the improvement on illusion, perception and understanding the level of interest of developed rehabilitation exercise. Then, the clinical trial to be conducted at Port Kembla Rehabilitation Hospital in Australia after all the necessary improvements have made and result will be reported soon.

\section{REFERENCES}

Al-Issa, H., Regenbrecht, H., \& Hale, L. (2012). Augmented reality applications in rehabilitation to improve physical outcomes. Physical Therapy Reviews, 17(1), 16-28.

Aung, Y. M., \& Al-Jumaily, A. (2012a, 24-27 June 2012). $A R$ based upper limb rehabilitation system. Paper presented at the 4th IEEE RAS \& EMBS International Conference on Biomedical Robotics and Biomechatronics (BioRob), Rome, Italy.

Aung, Y. M., \& Al-Jumaily, A. (2012b, 5-8 Aug. 2012). Shoulder rehabilitation with biofeedback simulation. Paper presented at the 2012 International Conference on Mechatronics and Automation (ICMA), Chengdu, China.

Aung, Y. M., \& Al-Jumaily, A. (2013). Neuromotor Rehabilitation System with Real-Time Biofeedback. International Journal of Computer Information Systems and Industrial Management Applications, 5, 550-556.

Denavit, J., \& Hartenberg, R. S. (1964). Kinematic Synthesis of Linkages. New York: McGraw-Hill.

Dinevan, A., Aung, Y. M., \& Al-Jumaily, A. (2011, 5-8 Dec. 2011). Human computer interactive system for fast recovery based stroke rehabilitation. Paper presented at the 11th International Conference on Hybrid Intelligent Systems (HIS).

Giraux, P., \& Sirigu, A. (2003). Illusory movements of the paralyzed limb restore motor cortex activity. NeuroImage, 20, Supplement 1(0), S107-S111.

Lee, M. M., Cho, H.-y., \& Song, C. H. (2012). The Mirror Therapy Program Enhances Upper-Limb Motor Recovery and Motor Function in Acute Stroke Patients. American Journal of Physical Medicine \& Rehabilitation, 91(8), 689-700.

Lin, K. C., Chen, Y. T., Huang, P. C., Wu, C. Y., Huang, W. L., Yang, H. W., . . . Lu, H. J. (2012). Effect of mirror therapy combined with somatosensory stimulation on motor recovery and daily function in stroke patients: A pilot study. Journal of the Formosan Medical Association(0).

Physical Disability Australia. (2013). What is physical disability? Retrieved May, 2013, from http://www.pda.org.au/what-is-physical-disability.

Regenbrecht, H., Hoermann, S., McGregor, G., Dixon, B., Franz, E., Ott, C., Hoermann, J. (2012). Visual 
manipulations for motor rehabilitation. Computers \& Graphics, 36(7), 819-834.

Riener, R., Frey, M., Bernhardt, M., Nef, T., \& Colombo, G. (2005, 28 June-1 July 2005). Human-centered rehabilitation robotics. Paper presented at the Rehabilitation Robotics, 2005. ICORR 2005. 9th International Conference on.

Thieme, H., Mehrholz, J., Pohl, M., Behrens, J., \& Dohle, C. (2013). Mirror therapy for improving motor function after stroke. Stroke, 44(1), e1-e2. 


\section{NEUROTECHNIX 2013}

International Congress on Neurotechnology, Electronics and Informatics

VILAMOURA, Algarve, Portugal

18 - 20 September, 2013

\section{PROCEEDINGS}

SPONSORED BY:

IITSTICC () MedlnRes
IN COOPERATION WITH:

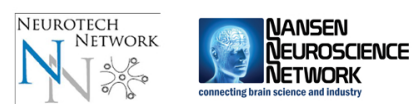

APezenc
IN COLLABORATION WITH:

antibodies 


\title{
NEUROTECHNIX
}

\section{3}

\author{
Proceedings of the \\ International Congress on Neurotechnology, \\ Electronics and Informatics
}

Vilamoura, Algarve, Portugal

18 - 20 September, 2013

Sponsored by

INSTICC - Institute for Systems and Technologies of Information, Control and Communication

In Cooperation with

Neurotech Network

Nansen Neuroscience Network

APEEGNC - Associação Portuguesa de EEG e Neurofisiologia Clínica SPN - Sociedade Portuguesa de Neurologia

Enlightenment FP7

In Collaboration with

antibodies-online.com - The Marketplace for Research Antibodies 
Copyright (C) 2013 SCITEPRESS - Science and Technology Publications All rights reserved

Edited by Ana Rita Londral, Pedro Encarnação and Jose Luis Pons

Printed in Portugal

ISBN: 978-989-8565-80-8

Depósito Legal: 363650/13

http://www.neurotechnix.org

neurotechnix.secretariat@insticc.org 


\section{BRIEF CONTENTS}

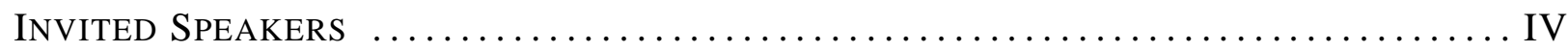

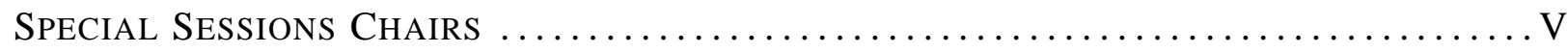

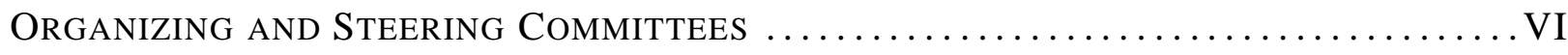

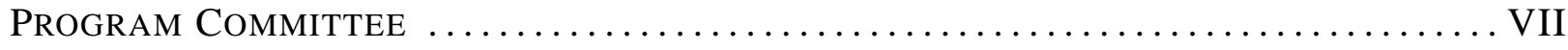

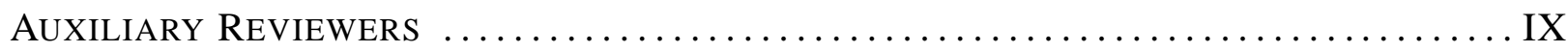

Special Sessions Program Committee $\ldots \ldots \ldots \ldots \ldots \ldots \ldots \ldots \ldots \ldots \ldots \ldots \ldots \ldots \ldots$

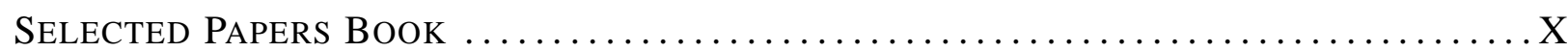

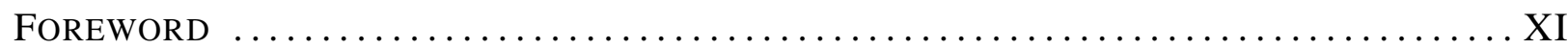

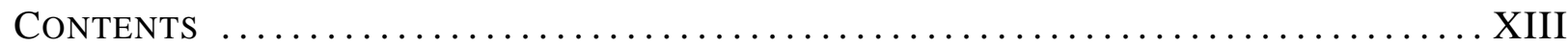




\title{
INVITED SPEAKERS
}

\author{
Kevin Warwick \\ University of Reading \\ U.K.
}

François Hug

The University of Queensland

Australia

Aldo Faisal

Imperial College London

U.K.

\section{Alexandre Castro-Caldas}

Portuguese Catholic University

Portugal 


\section{SPECial SeSSions Chairs}

\section{Special Session on Virtual and Augmented Reality Systems for UpPer Limbs REHABILITATION}

Alessandro de Mauro, Vicomtech-IK4, Spain

Iris Dimbwadyo Terrer, National Spinal Cord Injury Hospital - SESCAM, Spain

Gorka Epelde, Vicomtech-IK4, Applications for Independent living Group, Spain

\section{Special Session on Decoding the Neural Drive to Muscle through the Analysis of Motor} NEURON SPIKE TRAINS

Juan Álvaro Gallego, Spanish National Research Council (CSIC), Spain

Jose Luis Pons, Instituto de Automatica Industrial, Spain

\section{SPECIAL SESSion ON SENSORY FuSiOn FOR Diagnostics AND NEUROREHABILITATION}

Diego Torricelli, Consejo Superior de Investigaciones Cientificas (CSIC), Spain

Rafael Raya, Spanish National Council for Science Research, Spain

\section{Special Session on Wearable Robotics for Motion Assistance and Rehabilitation}

Nicola Vitiello, Scuola Superiore Sant'Anna, Italy

Samer Mohammed, Lissi - Université Paris-Est Créteil, France

Juan Moreno, CSIC, Spain

\section{SPECIAL SESSION ON BRAIN-COMPUTER INTERFACES AND BRAIN STIMULATION FOR NEUROREHABILITATION}

Martin Bogdan, Universität Leipzig, Germany

Ander Ramos-Murguialday, Eberhard-Karls-University, Germany

Armin Walter, Eberhard-Karls-University Tübingen, Germany

Francisco Perales, Uib, Spain 


\section{Organizing And Steering Committees}

\section{Conference Chair}

Ana Rita Londral, Universidade de Lisboa, Portugal

\section{Program Co-chairs}

Pedro Encarnação, Universidade Católica Portuguesa, Portugal Jose Luis Pons, Instituto de Automatica Industrial, Spain

\section{Proceedings Production}

Marina Carvalho, INSTICC, Portugal

Helder Coelhas, INSTICC, Portugal

Bruno Encarnação, INSTICC, Portugal

Ana Guerreiro, INSTICC, Portugal

Andreia Moita, INSTICC, Portugal

Raquel Pedrosa, INSTICC, Portugal

Vitor Pedrosa, INSTICC, Portugal

Sara Santiago, INSTICC, Portugal

José Varela, INSTICC, Portugal

\section{CD-ROM PRODUCTION}

Pedro Varela, INSTICC, Portugal

\section{Graphics Production and Webdesigner}

André Lista, INSTICC, Portugal

Mara Silva, INSTICC, Portugal

SeCRETARIAT

Cláudia Pinto, INSTICC, Portugal

\section{WEBMASTER}

Susana Ribeiro, INSTICC, Portugal 


\section{Program Committee}

Amr Abdel-Dayem, Laurentian University, Canada

Gregor Adriany, University of Minnesota, U.S.A.

Lyuba Alboul, Sheffield Hallam University, U.K.

Pedro Almeida, University of Lisbon, Portugal

Alexandre Andrade, Faculdade de Ciências da Universidade de Lisboa, Portugal

Helder Araújo, University of Coimbra, Portugal

Sabri Arik, Istanbul University, Turkey

Tetsuya Asai, Hokkaido University, Japan

Jose M. Azorin, Miguel Hernandez University, Spain

Reneta Barneva, State University of New York, U.S.A.

Ammar Belatreche, University of Ulster, U.K.

Alexandre Bernardino, Instituto Superior Técnico, Portugal

Fernando Brunetti, Consejo Superior de Investigaciones Científicas, Spain

Barbara Caputo, IDIAP Research Institute, Switzerland

Xin Chen, Georgia Health Sciences University, U.S.A.

Albert C. S. Chung, The Hong Kong University of Science and Technology, Hong Kong

Emmanuel Conchon, University of Toulouse, IRIT/ISIS, France

Lei Ding, University of Oklahoma, U.S.A.

Dominique Durand, Case Western Reserve, U.S.A.

Jimmy T. Efird, East Carolina Heart Institute, U.S.A.

Gary Egan, Monash University, Australia

Patrícia Figueiredo, Instituto Superior Técnico, Portugal

Alexander Fingelkurts, BM-Science - Brain \& Mind Technologies Research Centre, Finland
Andrew Fingelkurts, BM-Science - Brain \& Mind Technologies Research Centre, Finland

Anselmo Frizera, UFES, Brazil

Colin Fyfe, University of the West of Scotland, U.K.

Vasco Galhardo, Faculdade de Medicina Universidade do Porto, Portugal

Petia Georgieva, University of Aveiro, Portugal

Michele Giugliano, University of Antwerp, Belgium

Jordi Gonzàlez, Universitat Autònoma de Barcelona - Centre de Visió per Computador, Spain

Jay Gunkelman, Brain Science International, U.S.A.

Chung Y. Hsu, China Medical University, Taiwan

Xavier Intes, Rensselaer Polytechnic Institute, U.S.A.

Pasi Karjalainen, University of Eastern Finland, Finland

Jonghwa Kim, University of Augsburg, Germany

Frank Kirchner, DFKI, Germany

Andrzej Kloczkowski, Ohio State University, U.S.A.

Constantine Kotropoulos, Aristotle University of Thessaloniki, Greece

Ondrej Krejcar, University of Hradec Kralove, Czech Republic

Hongen Liao, The University of Tokyo, Japan

Diego Liberati, National Research Council, Italy

Xiao Liu, Brunel University, U.K.

Christos Loizou, Intercollege, Cyprus

Ana Rita Londral, Universidade de Lisboa, Portugal

Nigel Lovell, University of New South Wales, Australia

Mai S. Mabrouk, Misr University for Science and Technology, Egypt

Alessandro de Mauro, Vicomtech-IK4, Spain 


\section{Program Committee (CONT.)}

Javier Melenchón, Universitat Oberta de Catalunya, Spain

Paulo Mendes, University of Minho, Portugal

Susana Novais, Carnegie Mellon University, U.S.A.

Calogero Maria Oddo, Scuola Superiore Sant'Anna, Italy

Haluk Ogmen, University of Houston, U.S.A.

Joao Papa, Sao Paulo State University - Unesp, Brazil

Francisco Perales, Uib, Spain

George Perry, University of Texas at San Antonio, U.S.A.

Victor Pikov, Huntington Medical Research Institutes, U.S.A.

Armando J. Pinho, University of Aveiro, Portugal

Susana Pinto, Institute of Molecular Medicine Faculty of Medicine, University of Lisbon, Portugal

Gabriel Pires, Institute for Systems and Robotics Coimbra / Polytechnic Institute of Tomar, Portugal

Hemerson Pistori, Dom Bosco Catholic University, Brazil

Mirjana Popovic, University of Belgrade, Serbia

Ales Prochazka, Institute of Chemical Technology, Czech Republic

Rafael Raya, Spanish National Council for Science Research, Spain
Despina Sanoudou, Medical School, University of Athens, Greece

André Saúde, Federal University of Lavras, Brazil

Friedhelm Schwenker, University of Ulm, Germany

Mário Forjaz Secca, CEFITEC, Departamento de Fisica, FCT/UNL, Portugal

Tapio Seppänen, University of Oulu, Finland

Miguel Tavares da Silva, Instituto Superior Técnico, Portugal

Claudia Sommer, University of Würzburg, Germany

Armando J. Sousa, Faculdade de Engenharia da Universidade do Porto, Portugal

Sundaram Suresh, Nanyang Technological University, Singapore

João Manuel R. S. Tavares, FEUP - Faculdade de Engenharia da Universidade do Porto, Portugal

Marc Tittgemeyer, Max-Planck-Institut für neurologische Forschung, Germany

Diego Torricelli, Consejo Superior de Investigaciones Cientificas (CSIC), Spain

Carlos M. Travieso, University of Las Palmas de Gran Canaria, Spain

Nicola Vitiello, Scuola Superiore Sant'Anna, Italy

Zeyun Yu, University of Wisconsin at Milwaukee, U.S.A.

Inga Zerr, University of Göttingen, Germany

Djemel Ziou, Universite de Sherbrooke, Canada

\section{AuXiliary Reviewers}

Maria Laura Blefari, EPFL, Switzerland

Henrik Jörntell, Lund University, Sweden

\author{
Aikaterini Koutsou, CAR-CSIC, Spain \\ Cristina Santos, University of Minho, Portugal \\ Shingo Shimoda, RIKEN, Japan
}




\section{Special Sessions Program Committee}

\section{SPECIAL Session on Virtual AND Augmented REAlity Systems for UPPER LIMBS REHABILITATION}

Gorka Epelde, Vicomtech-IK4, Applications for Independent living Group, Spain

Nestor Garay-Vitoria, University of the Basque Country/Euskal herriko Unibertsitatea, Spain
Alessandro de Mauro, Vicomtech-IK4, Spain

Iris Dimbwadyo Terrer, National Spinal Cord Injury Hospital - SESCAM, Spain

\section{Special Session on Decoding the Neural Drive to Muscle through the Analysis of Motor Neuron Spike Trains}

Jakob Lund Dideriksen, Göttingen University, Germany

Aleš Holobar, University of Maribor, Slovenia

\section{SPECIAL SESSION ON SENSORY FUSION FOR DiAgNOSTICS AND NEUROREHABILITATION}

Rafael Raya, Spanish National Council for Science Research, Spain

\section{Special Session on Wearable Robotics for Motion Assistance And REHABILITATION}

Luka Ambrozic, Faculty of Electrical Engineering, University of Ljubljana, Slovenia

Alícia Casals, Institute for Bioengineering of Catalonia.IBEC and Universitat Politècnica de Catalunya.UPC, Spain

Marco Cempini, The Biorobotics Institute - Scuola Superiore Sant'Anna, Pisa, Italy

Mario Cortese, The Biorobotics Institute - Scuola Superiore Sant'Anna, Pisa, Italy

Simona Crea, The BioRobotics Institute - Scuola Superiore Sant'Anna, Pisa, Italy

Antonio J. del-Ama, National Hospital for Spinal Cord Injury, Spain

Georges Fried, Lissi - UPEC, France

Francesco Giovacchini, The Biorobotics Institute Scuola Superiore Sant'Anna, Pisa, Italy
Jian Huang, Huazhong University of Science and Technology, China

Ning Jiang, Universitätsmedizin Göttingen Georg-August-Universität, Germany

Kyoungchul Kong, Sogang University, Korea, Republic of

Stefan Lambrecht, CSIC, Spain

Samer Mohammed, Lissi - Université Paris-Est Créteil, France

Luis Montano, Universidad de Zaragoza, Spain

Juan Moreno, CSIC, Spain

Sehoon Oh, Sogang University, Korea, Republic of Hala Rifai, Lissi - Université Paris-Est Créteil, France

Jan Veneman, Tecnalia, Spain

Nicola Vitiello, Scuola Superiore Sant'Anna, Italy 


\section{Special Sessions Program Committee}

\section{SPECIAL SESSION ON BRAIN-COMPUTER INTERFACES AND BRAIN STIMULATION FOR NEUROREHABILITATION}

Martin Bogdan, Universität Leipzig, Germany

Francisco Perales, Uib, Spain
Ander

Ramos-Murguialday,

Eberhard-Karls-University, Germany

Armin Walter, Eberhard-Karls-University Tübingen, Germany

\section{Selected Papers Book}

A number of selected papers presented at NEUROTECHNIX 2013 will be published by Springer-Verlag in Springer Series in Computational Neuroscience. This selection will be done by the Conference Chair and Program Co-chairs, among the papers actually presented at the conference, based on a rigorous review by the NEUROTECHNIX 2013 Program Committee members. 


\section{FOREWORD}

This book contains the proceedings of the 1st International Congress on Neurotechnology, Electronics and Informatics (NEUROTECHNIX 2013).

NEUROTECHNIX 2013 is co-sponsored by INSTICC - Institute for Systems and Technologies of Information, Control and Communication and MedinRes - Medical Information and Research, held in cooperation with Neurotech Network, Nansen Neuroscience Network, Associação Portuguesa de EEG e Neurofisiologia Clínica, Sociedade Portuguesa de Neurologia and Fp7 Project Enlightenment, and held in collaboration with Antibodies Online.

The Congress Technical Program includes oral presentations (full papers, short papers, and posters) organized around several topics such as: Neuromuscular Diseases, Parkinson Disease, Developmental Disorders, Dementia, Epilepsy, Sleep Disorders, Multiple Sclerosis, Neuroinfections, Brain Tumors, Stroke, Traumatic Brain Injuries, Cerebral Palsy, Spinal Cord Injury, Vision and Hearing Disorders. All full papers and short papers were included in the proceedings. The congress includes also several thematic sessions organized by specialized researchers: VirtRehab 2013 - Virtual and Augmented Reality Systems for Upper Limbs Rehabilitation; DeNeuro 2013 - Decoding the Neural Drive to Muscle through the Analysis of Motor Neuron Spike Trains; SensoryFusion 2013 - Sensory Fusion for Diagnostics and Neurorehabilitation; RoboAssist 2013 - Wearable Robotics for Motion Assistance and Rehabilitation; and BrainRehab 2013 - Brain-computer Interfaces and Brain Stimulation for Neurorehabilitation. A major aspect of the program is the inclusion of a set of four plenary keynote lectures given by internationally distinguished researchers, namely: Kevin Warwick (University of Reading, United Kingdom), François Hug (University of Queensland, Australia), Aldo Faisal (Imperial College London, United Kingdom) and Alexandre Castro-Caldas (Catholic University of Portugal, Portugal).

NEUROTECHNIX received submissions from 21 countries, in all continents. To evaluate each submission, a double blind paper review was performed by the Program Committee, whose members are highly qualified researchers in the NEUROTECHNIX topic areas. A post-congress Special Issue of the Springer Series in Computational Neuroscience is planned for publication of extended and revised versions of a restricted number of high quality papers presented during NEUROTECHNIX 2013. All papers presented at this congress will be available at the SciTePress Digital Library.

Congresses are also meeting places where collaboration projects can emerge from social contacts amongst the participants. Therefore, in order to promote the development of research and professional networks, the congress includes in its social program a Congress Social Event \& Banquet in the evening of September 20.

We would like to express our thanks to all participants. First of all to the authors, whose quality work is the essence of this congress; secondly to all members of the Program Committee and auxiliary reviewers, who helped us with their expertise and valuable time. We 
would also like to deeply thank the invited speakers for their excellent contribution in sharing their knowledge and vision. Finally, a word of appreciation for the hard work of the secretariat: organizing a congress of this level is a task that can only be achieved by the collaborative effort of a dedicated and highly capable team.

\author{
Ana Rita Londral \\ Universidade de Lisboa, Portugal
}

Pedro Encarnação

Universidade Católica Portuguesa, Portugal

Jose Luis Pons

Instituto de Automatica Industrial, Spain 


\section{Contents}

\section{INVITED SPEAKERS}

\section{KEYNOTE SPEAKERS}

The Disappearing Human-Machine Divide Kevin Warwick

Analysis of Muscle Coordination in Sports - Perspectives from Electromyography and Elastography François Hug

Breaking into your Brain with Neurotechnology

Aldo Faisal

The Working Brain - Windows to the Outside World

Alexandre Castro-Caldas

\section{PAPERS}

\section{Full Papers}

Robotic Grasp Initiation by Gaze Independent Brain-controlled Selection of Virtual Reality Objects Christoph Reichert, Matthias Kennel, Rudolf Kruse, Hans-Jochen Heinze, Ulrich Schmucker, Hermann Hinrichs and Jochem W. Rieger

Striving for Better and Earlier Movement Prediction by Postprocessing of Classification Scores Sirko Straube, Anett Seeland and David Feess

A Low Cost Platform based on FES and Muscle Synergies for Postural Control Research and Rehabilitation

D. Galeano, F. Brunetti, D. Torricelli, S. Piazza and J. L. Pons

\section{Short PAPERS}

Proposal of a P300-based BCI Speller using a Predictive Text System Ricardo Ron Angevin and Leandro da Silva-Sauer

Memory and Processing Efficient Formula for Moving Variance Calculation in EEG and EMG Signal Processing Mario Michael Krell, Marc Tabie, Hendrik Wöhrle and Elsa Andrea Kirchner

A Dataflow-based Mobile Brain Reading System on Chip with Supervised Online Calibration - For Usage without Acquisition of Training Data

Hendrik Woehrle, Johannes Teiwes, Mario Michael Krell, Elsa Andrea Kirchner and Frank Kirchner

A Method to Detect Keystrokes using Accelerometry to Quantify Typing Rate and Monitor Neurodegenerative Progression

Ana Londral, Mafalda Câmara, Hugo Gamboa, Mamede de Carvalho, Anabela Pinto and Luís Azevedo

Comparison of Neural Networks for Prediction of Sleep Apnea

Yashar Maali and Adel Al-Jumaily 


\section{SPECIAL SESSION ON VIRTUAL AND AUGMENTED REALITY SYSTEMS FOR UPPER LIMBS REHABILITATION}

\section{Full Papers}

Virtual Arm Representation and Multimodal Monitoring for the Upper Limb Robot Assisted Teletherapy

Gorka Epelde, Xabier Valencia, Aitor Ardanza, Elsa Fanchon, Alessandro De Mauro,

Francisco Molina Rueda, Eduardo Carrasco and Shabs Rajasekharan

Clinical, Functional and Kinematic Correlations using the Virtual Reality System Toyra ${ }^{\circledR}$ as Upper Limb Rehabilitation Tool in People with Spinal Cord Injury

Iris Dimbwadyo-Terrer, Fernando Trincado-Alonso, Ana de los Reyes-Guzmán, Alberto Bernal-Sahún, Patricia López-Monteagudo, Begoña Polonio-López and Ángel Gil-Agudo

Rehabilitation for Children while Playing with a Robotic Assistant in a Serious Game

L. V. Calderita, P. Bustos, C. Suárez Mejías, B. Ferrer González and A. Bandera

\section{ShORT PAPERS}

Illusion Approach for Upper Limb Motor Rehabilitation

Yee Mon Aung and Adel Al-Jumaily

New Developments in the Gesture Therapy Platform - Past, Present and Future of our Research Felipe Orihuela-Espina, Paloma Álvarez-Cardenas, Lorena Palafox, Israel Sánchez-Villavicencio, Alberto L. Morán, Jorge Hérnandez-Franco and Luis Enrique Sucar

\section{SPECIAL SESSION ON DECODING THE NEURAL DRIVE TO MUSCLE THROUGH THE ANALYSIS OF MOTOR NEURON SPIKE TRAINS}

\section{ShORT PAPERS}

Multi Channel Surface EMG - Detection and Conditioning

M. Gazzoni and U. Barone

On the Impact of Pathological Tremor Intensity on Noninvasive Characterization of Motor Unit Discharge Properties

Petra Povalej Bržan, Vojko Glaser, Simon Zelič, Juan Álvaro Gallego, Juan Pablo Romero Muñoz and Aleš Holobar

Motor Unit Properties and Underlying Determinants in Pathological Tremor

J. A. Gallego, J. L. Dideriksen, A. Holobar, J. P. Romero, J. L. Pons, E. Rocon and D. Farina

\section{SPECIAL SESSION ON SENSORY FUSION FOR DIAGNOSTICS AND NEUROREHABILITATION}

\section{Full Papers}

Assessment of Walker-assisted Human Interaction from LRF and Wearable Wireless Inertial Sensors

Maria Martins, Carlos Cifuentes, Arlindo Elias, Valmir Schneider, Anselmo Frizera and Cristina Santos

Human-like Sensor Fusion Mechanisms in a Postural Control Robot

Georg Hettich, Vittorio Lippi and Thomas Mergner 
Assessment of the Suitability of the Motorized Ankle-Foot Orthosis as a Diagnostic and Rehabilitation Tool for Gait

Guillermo Asín, Filipe A. Barroso, Juan C. Moreno and José L. Pons

Error Augmented Robotic Rehabilitation of the Upper Limb - A Review

Aris C. Alexoulis-Chrysovergis, Andrew Weightman, Emma Hodson-Tole and Frederik J. A. Deconinck

\section{SPECIAL SESSION ON WEARABLE ROBOTICS FOR MOTION ASSISTANCE AND REHABILITATION}

\section{Full Papers}

A Double-differential Actuation for an Assistive Hip Orthosis - Specificities and Implementation Jeremy Olivier, Mohamed Bouri and Hannes Bleuler

Feasibility of Hybrid Gait Training with Kinesis Overground Robot for Persons with incomplete Spinal Cord Injury

Antonio J. del-Ama, Ángel Gil-Agudo, José L. Pons and Juan C. Moreno

A Light-weight Exoskeleton for Hip Flexion-extension Assistance

Francesco Giovacchini, Matteo Fantozzi, Mariele Peroni, Matteo Moisè, Marco Cempini, Mario Cortese,

Dirk Lefeber, Maria Chiara Carrozza and Nicola Vitiello

Human Motion Assistance using Walking-aid Robot and Wearable Sensors

Jian Huang, Wenxia Xu, Zhen Shu and Samer Mohammed

Human-based Lower Limb Movement Assistance and Rehabilitation through an Actuated Orthosis Samer Mohammed, Hala Rifai, Walid Hassani and Yacine Amirat

\section{ShORT PAPERS}

Humanoids Meet Rehabilitation - Concept and Potential

Diego Torricelli and Jose L. Pons

Real-time Classification of Finger Movements using Two-channel Surface Electromyography Khairul Anam and Adel Al-Jumaily

Ankle-Knee Prosthesis with Powered Ankle and Energy Transfer - Development of the CYBERLEGs Alpha-Prototype

Louis Flynn, Joost Geeroms, Rene Jimenez-Fabian, Bram Vanderborght, Nicola Vitiello and Dirk Lefeber

\section{SPECIAL SESSION ON BRAIN-COMPUTER INTERFACES AND BRAIN STIMULATION FOR NEUROREHABILITATION}

\section{Full Paper}

Efficiency of SSVEF Recognition from the Magnetoencephalogram - A Comparison of Spectral Feature Classification and CCA-based Prediction

Christoph Reichert, Matthias Kennel, Rudolf Kruse, Hermann Hinrichs and Jochem W. Rieger 


\section{Short Papers}

Dynamics of a Stimulation-evoked ECoG Potential During Stroke Rehabilitation - A Case Study Armin Walter, Georgios Naros, Martin Spüler, Wolfgang Rosenstiel, Alireza Gharabaghi and Martin Bogdan

A Serious Game Application using EEG-based Brain Computer Interface

Francisco José Perales and Esperança Amengual

Monitoring Depth of Hypnosis under Propofol General Anaesthesia - Granger Causality and Hidden Markov Models

Nicoletta Nicolaou and Julius Georgiou

AUTHOR INDEX

263 